\title{
An isolated childhood myeloid sarcoma with germline MSH6 mutation-a case report
}

\author{
Yu Liu ${ }^{1 \#}$, MaiMaiTi GuLiBaHa ${ }^{1 \#}$, Ying-Bin Yue ${ }^{1}$, Ming-Wei Li $^{1}$, Shan-Bo Cao ${ }^{2}$, Mei Yan ${ }^{1}$ \\ ${ }^{1}$ Pediatric Department, The First Affiliated Hospital of Xinjiang Medical University, Urumqi, China; ${ }^{2}$ Lab of Gene, Acornmed Biotechnology Co., \\ Ltd. Beijing Economic and Technological Development Zone, Beijing, China \\ \#These authors contributed equally to this work as co-first authors. \\ Correspondence to: Mei Yan. Pediatric Department, The First Affiliated Hospital of Xinjiang Medical University, Urumqi 830054, China. \\ Email: yan10mei25@126.com.
}

\begin{abstract}
Myeloid sarcoma (MS) is a type of malignant tumor that originates in the bone marrow. This study reports on the treatment of an 11-year-old Uygur girl with a 15-day history of fever and paroxysmal cough, accompanied by right hip pain. During treatment, fatigue and anemia developed, physical strength decreased, and a few petechiae were seen in the lower extremities. Multiple enlarged lymph nodes were palpable in the neck, with slight congestion in the pharynx. Routine blood screening showed three major myeloid lineage abnormalities. Pathological examination revealed the presence of CD10 (-), CD99 (+), CD20 (+), CD3 (-), CD117 (weak+), CD34 (unclear location), TdT (-), Pax5 (-), Ki-67 (50\%+), MPO $(-)$, and CD43 (+). The patient was eventually diagnosed with isolated MS. After chemotherapy, no small particles were observed in bone marrow morphology. Complete remission was confirmed by flow cytometric detection of minimal residual disease. Genomic DNA was subjected to targeted sequencing of 236 gene panels to detect somatic mutations and the MSH6 c.3953_3954insAA p.R1318fs germline mutation. Unfortunately, the patient was subsequently lost to follow-up. To our knowledge, an MSH6 germline mutation had not previously been reported in children with MS, and we speculated that an MSH6 germline mutation led to genomic instability, triggering a somatic mutation in multiple genes and ultimately led to the development of MS in this patient. It is suggested that rare base abnormalities may be involved in the development of isolated myeloid sarcomas (IMS).
\end{abstract}

Keywords: Isolated myeloid sarcoma (IMS); MSH6; somatic mutations; chemotherapy; case report

Submitted Jun 04, 2021. Accepted for publication Aug 19, 2021.

doi: $10.21037 / \mathrm{tp}-21-326$

View this article at: https://dx.doi.org/10.21037/tp-21-326

\section{Introduction}

Myeloid sarcoma (MS) is a rare soft tissue tumor composed of myeloid blasts in extramedullary sites and has a poor prognosis (1). MS may occur concurrently with myelodysplastic syndrome (MDS), myeloproliferative disorders (MPN), or acute myeloid leukemia (AML) (2). Isolated myeloid sarcoma (IMS) is one of the specific types of soft tissue tumors with the lowest incidence of MS, without evidence of MDS, MPN, or AML, and with a high risk of transformation AML within months or years (3).

MutS homolog 6 (MSH6) is a member of a group of mismatch repair (MMR) genes involved in the recognition and repair of mismatched nucleotides (4,5). Defects in MSH6 during embryonic development may affect the stability of the DNA genome, leading to the occurrence of somatic mutations, which can result in many types of malignancies, such as colorectal cancer, endometrial cancer, leukemia, or lymphoma (6-8).

The molecular factors that trigger the onset of MS have not been elucidated. Although some AML associated gene mutations have been identified in MS (9), the spectrum of gene mutations in MS is poorly understood. Therefore, more studies are needed to explore the mutational landscape 
in-depth to understand the onset and progression of MS and potentially broaden risk-adapted treatment options for MS patients. We present the following case in accordance with the CARE reporting checklist (available at https:// dx.doi.org/10.21037/tp-21-326).

\section{Case presentation}

An 11-year-old Uyghur girl with a 15-day history of fever and paroxysmal cough without obvious triggers was examined and treated. Due to suspected pneumonia, the patient received symptomatic treatment with oral spectinomycin at the local hospital for 3 days and intravenous cefuroxime sodium anti-infective treatment for 2 days. The cough slightly improved, but the body temperature did not return to normal. She then developed right hip pain, which was evident during post-treatment activity. The patient attended our hospital for treatment on 15-Nov-2018. During the illness, the patient's main symptoms were fatigue and facial pallor, no significant change in weight but decreased physical strength, the appearance of pale oral mucocutaneous lesions, and petechiae visible in the lower limbs. Swelling of cervical lymph nodes at multiple sites, mild congestion in the pharynx, and no swelling of tonsils can be touched.

Routine blood screening showed three major myeloid lineage abnormalities, with a white blood cell count of $1.20 \times 10^{9} / \mathrm{L}$, neutrophil count of $0.11 \times 10^{9} / \mathrm{L}$, lymphocyte count of $1.05 \times 10^{9} / \mathrm{L}$, red blood cell count of $2.02 \times 10^{12} / \mathrm{L}$, hemoglobin of $66 \mathrm{~g} / \mathrm{L}$, and platelet count of $19 \times 10^{9} / \mathrm{L}$. Immunophenotypic testing showed AML subtype AML-M2 (predominantly expressing HLA-DR, CD7, CD13, CD33, CD3, CD3CD38, CD117, and CD123). Lymphocytes comprised approximately $38 \%$ of the nuclear cells, with an elevated CD3+ CD8+ T lymphocytes proportion. Bone marrow biopsy showed numerous immature cells, and morphological features supported the diagnosis of acute leukemia. However, bone marrow morphology revealed that nuclear cell count was 0.06 . Taken together, these results show that the patient did not meet the diagnostic criteria for AML-M2. The patient chose to be discharged from the hospital due to financial reasons, and no further diagnosis could be made.

On 27-Dec-2018, the patient review showed no abnormalities. Bone marrow biopsy showed normal bone tissue proliferation with trilineage cells evident and a generally normal granulocyte/erythrocyte ratio. Granulocytes were observed to be mainly in the maturation stage. Megakaryocytes were scattered, and macrophages and megakaryocytes were seen. The mesenchymal reticular fibers showed mild hyperplasia. Following immunohistochemistry, no obvious neoplastic lesion was found in this tissue biopsy. Bone marrow morphology was suggestive of active bone proliferation with $23 \%$ granulocytes and readily observable megakaryocytes. No obvious developmental abnormalities were found by immunophenotypic testing.

The patient attended our hospital again starting 03-Mar-2019 for 20 days after finding a head mass. Immunohistochemical staining of the mass found CD10 (-), CD99 (+), CD20 (+), CD3 (-), CD117 (weak +), CD34 (unclear location), TdT (-), Pax5 (-), Ki-67 (50\%+), MPO (-), and CD43 (+) (Figure 1). Hematoxylin and eosin staining of the mass revealed intermediate-sized cells with abundant cytoplasm, slightly irregular karyotype, diffusely organized in sheets, and an infiltrative growth pattern. On review of the immunohistochemical and histochemical staining results combined, the patient was ultimately diagnosed as having an isolated myelosarcoma (Figure 2A). Acute leukemia was excluded due to a blast count of $4 \%$. The patient received chemotherapy according to the CCLG-2015 protocol on 28-Mar-2019. DAH regimen chemotherapy was performed from 28-Mar-2019 to 03 Apr-2019. Bone marrow morphology showed no small particles. Detection of minimal residual disease (MRD) by flow cytometry indicated complete remission (Figure 2B). The patient then received IAE regimen chemotherapy from 27-May-2019 to 02-June-2019. Unfortunately, due to economic reasons, the patient chose to be discharged after treatment and was then lost to follow-up.

DAH regimen chemotherapy: daunorubicin $40 \mathrm{mg} /$ time D1, D3, D5 $\left(40 \mathrm{mg} / \mathrm{m}^{2}\right)$, cytarabine $100 \mathrm{mg} /$ time D1D7 $\left(100 \mathrm{mg} / \mathrm{m}^{2}\right)$, and HHT $3 \mathrm{mg} /$ time D1-D5 $\left(3 \mathrm{mg} / \mathrm{m}^{2}\right)$ from 26-March-2019 to 01-April-2019, and 17-April-2019, promptly 21 days of this chemotherapy plan check bone marrow cell morphology and MRD examination.

May 21 June 2 line start IAE regimen chemotherapy: nor daunorubicin $10 \mathrm{mg} /$ time D1, D3, D5 $\left(10 \mathrm{mg} / \mathrm{m}^{2}\right)$, cytarabine $110 \mathrm{mg} / \mathrm{time} \mathrm{D} 1-\mathrm{D} 7\left(100 \mathrm{mg} / \mathrm{m}^{2}\right)$, and etoposide $100 \mathrm{mg} /$ time D1-D5 $\left(100 \mathrm{mg} / \mathrm{m}^{2}\right)$. Chemotherapy was stopped due to fever on 22-May-2019 and continued on 28May-2019.

Targeted sequencing of 236 genes was performed on patient saliva and bone marrow samples to detect gene mutations in genomic DNA. This revealed that the patient carried the germline MSH6 c.3953_3954insAA p.R1318fs 

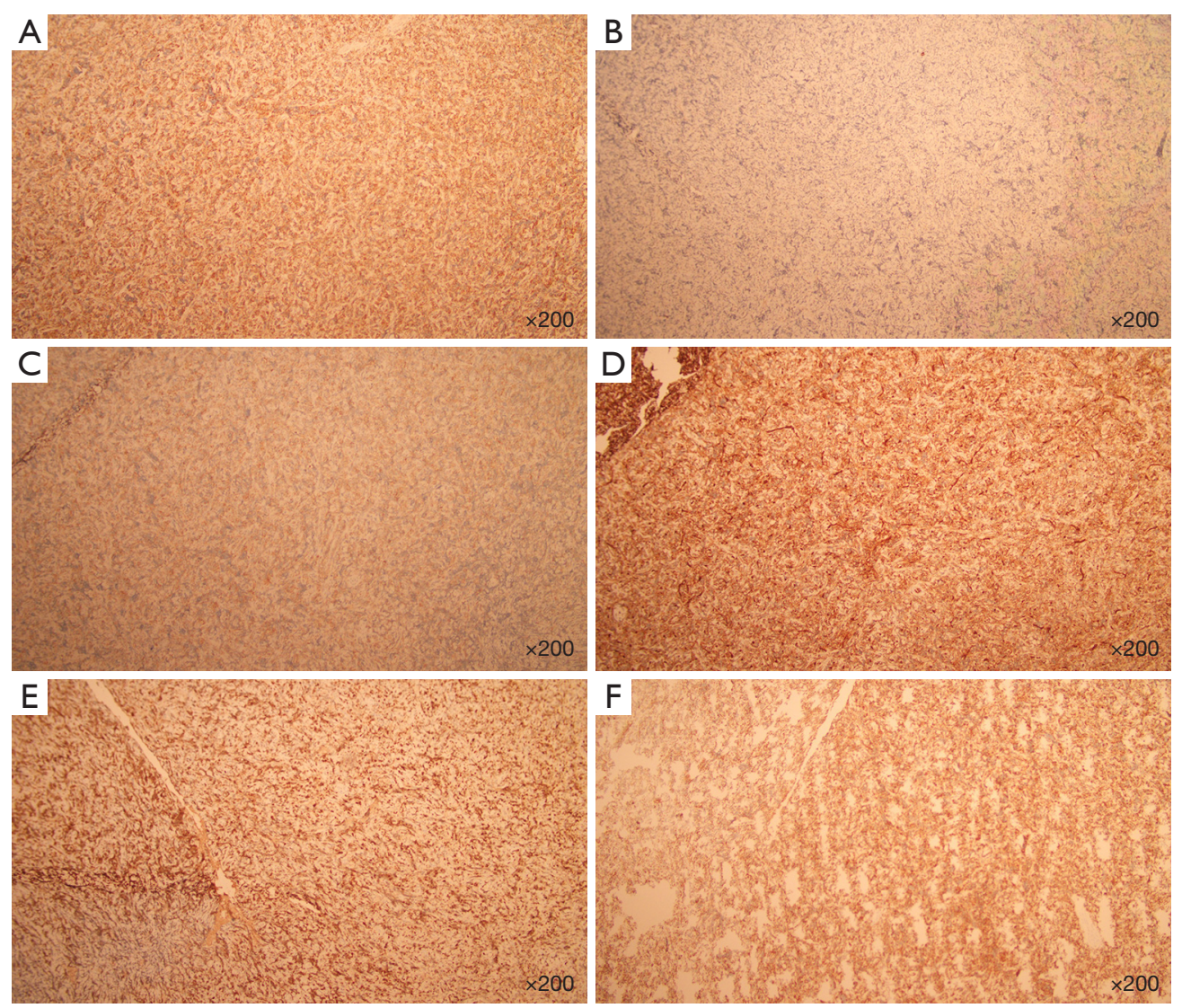

Figure 1 Immunohistochemical staining of tumor tissues (original magnification ×200). (A) CD99 (+); (B) CD20 (+); (C) CD117 (+); (D) CD34 (+); (E) Ki-67 (+); (F) CD43 (+).

mutation and low frequency of other genes such as $\mathrm{SH} 2 \mathrm{~B} 3$, USH2A, and SF1 (Table 1). We predicted that the MSH6-p. R1318fs mutation caused a conformational change of the protein by using the SWISS-MODEL Interactive Workspace (Figure 3A,3B).

All procedures performed in studies involving human participants were in accordance with the ethical standards of the institutional and/or national research committee(s) and with the Helsinki Declaration (as revised in 2013). Written informed consent was obtained from the patient for publication of this case report and accompanying images. A copy of the written consent is available for review by the editorial office of this journal.

\section{Discussion}

We described a rare, IMS in a child patient, in which the germline MSH6 c.3953_3954insAA p.R1318fs mutation was detected. We speculated that the germline MSH6 mutation caused genomic instability, triggering multiple somatic mutations and finally leading to the onset of MS in this patient. In addition, the myeloperoxidase (MPO)negative result in this patient after our analysis may be due to two reasons. Firstly, this specimen was derived from the head mass and might be affected by the specimen extrusion process, resulting in the immunohistochemical results. Secondly, tumor cells of this patient's myeloid sarcoma might be derived from progenitor cells given the small number of poorly differentiated myeloid primitive cells, which might be negative for MPO.

Many literature reports have detected MSH6 mutations in MSH6-related diseases, and multiple mutation sites have been found in various diseases (9-12). Biallelic pathogenic mutations in MSH6 have also been identified in patients with various hematologic malignancies, such as MDS or AML, but have not been reported in patients with MS (8,13-20). To our knowledge, the present study is the first to identify germline MSH6 mutations in MS 

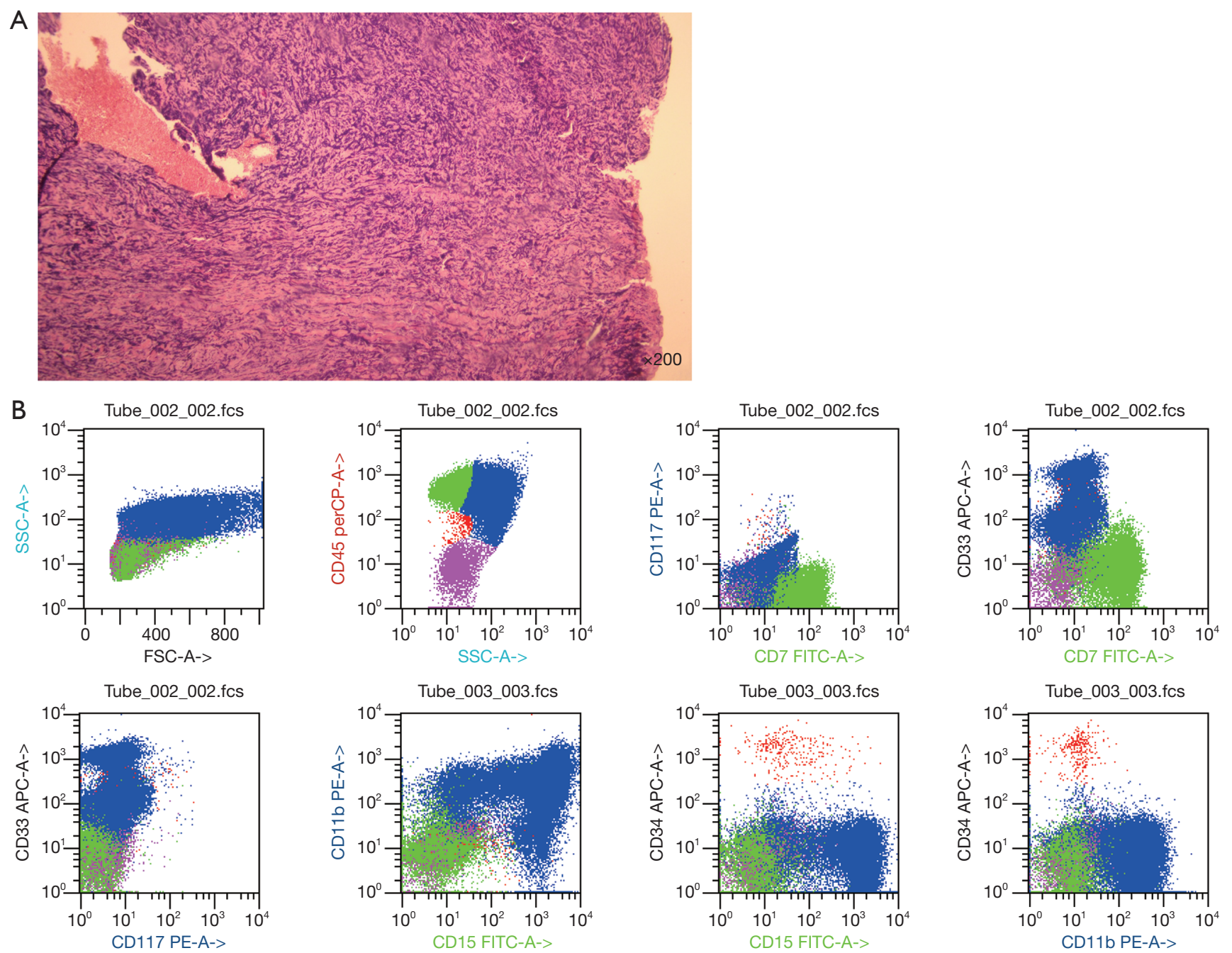

Figure 2 Myeloid sarcoma involving the head mass of an 11-year-old girl. (A) Low-power view showing the infiltrative and destructive pattern of growth of malignant cells (hematoxylin and eosin, original magnification $\times 200$ ); (B) detection of measurable residual disease by multicolor flow cytometry of bone marrow.

patients. According to the dbSNP database, the population mutation frequency of the MSH6-p.R1318fs mutation site in the healthy population is very low, and currently, the MSH6-p.R1318fs mutation site has only been reported in Hereditary nonpolyposis colorectal cancer (HNPCC) $(21,22)$. Our study found that MSH6-p.R1318fs mutation may cause a conformational change of the protein. We can infer that this region is highly conserved and that the mutation may result in a functional alteration of the MSH6 protein.

In addition, in our case, we report for the first time that $\mathrm{SH} 2 \mathrm{~B} 3$ somatic mutations were found in IMS patients. $\mathrm{Sh} 2 \mathrm{~b}$ adaptor protein 3 (SH2B3), a negative regulator of multiple tyrosine kinase signaling pathways and cytokine signaling pathways, plays a key role in hematopoiesis by inhibiting the activation of STAT3 phosphorylation through binding to JAK2 (23-25). Researchers have confirmed that SH2B3 mutations are associated with the occurrence and development of myeloproliferative neoplasms (MPN) or B-cell acute lymphoblastic leukemia (ALL) $(26,27)$. Therefore, SH2B3 may have an impact on the pathogenesis of MS. Meanwhile, a USH2A mutation was also detected in this MS patient. Mutations in the USH2A gene are associated with Usher syndrome type II, which is characterized by hearing loss and vision loss (28-30). In some IMS patients, Eyelid tumors or patients with acute 
Table 1 Gene mutations in IMS patients

\begin{tabular}{|c|c|c|c|}
\hline Gene & VAF (\%) & HGVS & ExonicFunc_refGene \\
\hline$H L A-D R B 1$ & 53.17 & NM_002124: c.T200C (p.V67A) & Nonsynonymous SNV \\
\hline$R U N \times 1$ & 6.86 & NM_001754: c.1256T>G (p.V419G) & Nonsynonymous SNV \\
\hline USH2A & 2.40 & NM_206933: c.8974G>T (p.E2992X) & Stopgain \\
\hline $\mathrm{ROBO} 2$ & 1.88 & $\begin{array}{l}\text { NM_002942: c.3226delC (p.P1076fs) NM_001290039:c.3238delC } \\
\text { (p.P1080fs); NM_001290040: c.3238delC (p.P1080fs); } \\
\text { NM_001290065:c.1447delC (p.P483fs) }\end{array}$ & Frameshift deletion \\
\hline $\mathrm{SH} 2 \mathrm{~B} 3$ & 1.79 & NM_005475: c.1618C>T (p.Q540X) & Stopgain \\
\hline PDGFRB & 1.72 & NM_002609: c.300C>T (p.C100C) & Synonymous SNV \\
\hline JAK1 & 1.34 & NM_002227: c.1815C>T (p.Y605Y) & Synonymous SNV \\
\hline$C C D C 168$ & 1.13 & NM_001146197: c.17048delA (p.K5683fs) & Frameshift deletion \\
\hline NTRK3 & 0.95 & NM_001012338: c.1682G>A (p.S561N) & Nonsynonymous SNV \\
\hline NOTCH1 & 0.92 & NM_017617: c.4732_4734del (p.1578_1578del) & Nonframeshift deletion \\
\hline PCLO & 0.88 & NM_033026: c.1486_1545del (p.496_515del) & Nonframeshift deletion \\
\hline ATRX & 0.82 & NM_000489: c.6674_6676del (p.2225_2226del) & Nonframeshift deletion \\
\hline NSD2 & 0.75 & NM_007331: c.1886_1888del (p.629_630del) & Nonframeshift deletion \\
\hline
\end{tabular}

SNV, single nucleotide variation.

A



Wild-type
B

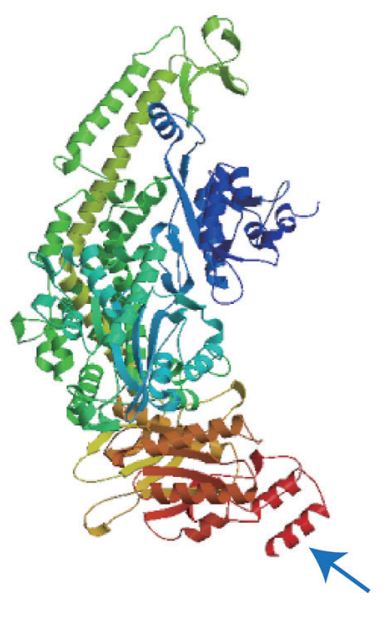

Mutated-type

Figure 3 Comparison of the protein conformation of the wild-type MSH6 and mutated-type MSH6 predicted by SWISS-MODEL Interactive Workspace. (A) Protein conformation of Wild-type MSH6; (B) protein conformation of mutated-type MSH6 which occurred in the location of MSH6 c.3953_3954insAA p.R1318fs. The blue arrows indicate the changed location. Blue arrows refer to the location of MSH6 c.3953_3954insAA p.R1318fs. 
leukemia have been reported to develop eyelid myeloid sarcomas during chemotherapy $(3,31,32)$. We speculate that USH2A mutations may be the cause of MS occurring on the eyelids. While no clinical signs of USH2A related symptoms were found in the patient we reported on; low frequency mutations occurred in both $\mathrm{SH} 2 \mathrm{~B} 3$ and USH2A genes in this case, so whether they are involved in the molecular mechanism of disease occurrence needs further exploration.

Isolated MS carries a high risk of progression to AML (3). Currently, different genetic variations in AML-related genes such as nucleophosmin (NPM1), FMS-like tyrosine kinase 3 (FLT3), KIT, KRAS, WT1, TP53, RUNX1, and others, have been identified in MS patients (33-35). However, in our study, only RUNX1 mutations were detected in MS patients. This may be mainly due to the occurrence of somatic mutations as a cumulative process involved with germline MSH6 mutations, a single mutation often being insufficient to cause malignant transformation.

Taken together, we speculate that germline MMR mutations may contribute to the pathogenesis of MS. Germline MMR mutations promote DNA instability, leading to progressive accumulation of somatic mutations that may confer some clinical specificity. We recommend that patients with MS, and their relatives, be considered for MMR-related gene mutation testing. The identification of germline MMR mutations will facilitate the implementation of effective surveillance programs for mutation carriers.

\section{Acknowledgments}

Funding: None.

\section{Footnote}

Reporting Checklist: The authors have completed the CARE reporting checklist. Available at https://dx.doi. org/10.21037/tp-21-326

Conflicts of Interest: All authors have completed the ICMJE uniform disclosure form (available at https://dx.doi. org/10.21037/tp-21-326). Dr. Shanbo Cao reported that he is an employee of Acornmed Biotechnology Co., Ltd. Beijing Economic and Technological Development Zone. The authors have no other conflicts of interest to declare.

Ethical Statement: The authors are accountable for all aspects of the work in ensuring that questions related to the accuracy or integrity of any part of the work are appropriately investigated and resolved. All procedures performed in studies involving human participants were in accordance with the ethical standards of the institutional and/or national research committee(s) and with the Helsinki Declaration (as revised in 2013). Written informed consent was obtained from the patient for publication of this case report and accompanying images. A copy of the written consent is available for review by the editorial office of this journal.

Open Access Statement: This is an Open Access article distributed in accordance with the Creative Commons Attribution-NonCommercial-NoDerivs 4.0 International License (CC BY-NC-ND 4.0), which permits the noncommercial replication and distribution of the article with the strict proviso that no changes or edits are made and the original work is properly cited (including links to both the formal publication through the relevant DOI and the license). See: https://creativecommons.org/ licenses/by-nc-nd/4.0/.

\section{References}

1. Aznab M, Kamalian N, Beiki O, et al. Myeloid Sarcoma of the peritoneum at older ages: A case report and review of literature. Int J Hematol Oncol Stem Cell Res 2015;9:50-4.

2. Avni B, Koren-Michowitz M. Myeloid sarcoma: current approach and therapeutic options. Ther Adv Hematol 2011;2:309-16.

3. Mitkowski D, Gil L. Isolated myeloid sarcoma as the first manifestation of acute myeloid leukemia: a case study. Clin Case Rep 2017;5:1802-6.

4. Gassman NR, Clodfelter JE, McCauley AK, et al. Cooperative nuclear localization sequences lend a novel role to the N-terminal region of MSH6. PLoS One 2011;6:e17907.

5. Zinovkina LA. Mechanisms of Mitochondrial DNA Repair in Mammals. Biochemistry (Mosc) 2018;83:233-49.

6. Barnetson RA, Tenesa A, Farrington SM, et al. Identification and survival of carriers of mutations in DNA mismatch-repair genes in colon cancer. $\mathrm{N}$ Engl J Med 2006;354:2751-63.

7. Ripperger T, Schlegelberger B. Acute lymphoblastic leukemia and lymphoma in the context of constitutional mismatch repair deficiency syndrome. Eur J Med Genet 
2016;59:133-42.

8. Ripperger T, Beger C, Rahner N, et al. Constitutional mismatch repair deficiency and childhood leukemia/ lymphoma--report on a novel biallelic MSH6 mutation. Haematologica 2010;95:841-4.

9. Choi M, Jeon YK, Sun CH, et al. RTK-RAS pathway mutation is enriched in myeloid sarcoma. Blood Cancer J 2018;8:43.

10. Pinto C, Veiga I, Pinheiro M, et al. MSH6 germline mutations in early-onset colorectal cancer patients without family history of the disease. Br J Cancer 2006;95:752-6.

11. Pinto C, Pinheiro M, Peixoto A, et al. Co-occurrence of nonsense mutations in MSH6 and MSH2 in Lynch syndrome families evidencing that not all truncating mutations are equal. J Hum Genet 2016;61:151-6.

12. Castellsagué E, Liu J, Volenik A, et al. Characterization of a novel founder MSH6 mutation causing Lynch syndrome in the French Canadian population. Clin Genet 2015;87:536-42.

13. Bakry D, Aronson M, Durno C, et al. Genetic and clinical determinants of constitutional mismatch repair deficiency syndrome: report from the constitutional mismatch repair deficiency consortium. Eur J Cancer 2014;50:987-96.

14. Bougeard G, Olivier-Faivre L, Baert-Desurmont S, et al. Diversity of the clinical presentation of the MMR gene biallelic mutations. Fam Cancer 2014;13:131-5.

15. Etzler J, Peyrl A, Zatkova A, et al. RNA-based mutation analysis identifies an unusual MSH6 splicing defect and circumvents PMS2 pseudogene interference. Hum Mutat 2008;29:299-305.

16. Hoell JI, Gombert M, Ginzel S, et al. Constitutional mismatch repair-deficiency and whole-exome sequencing as the means of the rapid detection of the causative MSH6 defect. Klin Padiatr 2014;226:357-61.

17. Ilencikova D, Sejnova D, Jindrova J, et al. High-grade brain tumors in siblings with biallelic MSH6 mutations.

Pediatr Blood Cancer 2011;57:1067-70.

18. Lavoine N, Colas C, Muleris M, et al. Constitutional mismatch repair deficiency syndrome: clinical description in a French cohort. J Med Genet 2015;52:770-8.

19. Peters A, Born H, Ettinger R, et al. Compound heterozygosity for MSH6 mutations in a pediatric lymphoma patient. J Pediatr Hematol Oncol 2009;31:113-5.

20. Scott RH, Mansour S, Pritchard-Jones K, et al. Medulloblastoma, acute myelocytic leukemia and colonic carcinomas in a child with biallelic MSH6 mutations. Nat Clin Pract Oncol 2007;4:130-4.

21. Raskin L, Schwenter F, Freytsis M, et al. Characterization of two Ashkenazi Jewish founder mutations in MSH6 gene causing Lynch syndrome. Clin Genet 2011;79:512-22.

22. Goldberg Y, Porat RM, Kedar I, et al. An Ashkenazi founder mutation in the MSH6 gene leading to HNPCC. Fam Cancer 2010;9:141-50.

23. Willman CL. SH2B3: a new leukemia predisposition gene. Blood 2013;122:2293-5.

24. Bersenev A, Wu C, Balcerek J, et al. Lnk constrains myeloproliferative diseases in mice. J Clin Invest 2010;120:2058-69.

25. Perez-Garcia A, Ambesi-Impiombato A, Hadler M, et al. Genetic loss of SH2B3 in acute lymphoblastic leukemia. Blood 2013;122:2425-32.

26. Pardanani A, Lasho T, Finke C, et al. LNK mutation studies in blast-phase myeloproliferative neoplasms, and in chronic-phase disease with TET2, IDH, JAK2 or MPL mutations. Leukemia 2010;24:1713-8.

27. Gu Y, Han Q, McGrath M, et al. Clinical significance of novel SH2B 3 mutations in adult Chinese acute lymphoblastic leukemia patients. Leuk Res 2018;72:67-70.

28. Kimberling WJ, Weston MD, Möller C, et al. Gene mapping of Usher syndrome type IIa: localization of the gene to a 2.1-cM segment on chromosome 1q41. Am J Hum Genet 1995;56:216-23.

29. Baux D, Larrieu L, Blanchet C, et al. Molecular and in silico analyses of the full-length isoform of usherin identify new pathogenic alleles in Usher type II patients. Hum Mutat 2007;28:781-9.

30. Huang L, Mao Y, Yang J, et al. Mutation screening of the USH2A gene in retinitis pigmentosa and USHER patients in a Han Chinese population. Eye (Lond) 2018;32:1608-14.

31. Montoro J, Tormo M. Images in clinical medicine. Myeloid sarcoma. N Engl J Med 2013;369:2332.

32. Kang H, Takahashi Y, Takahashi E, et al. Myeloid Sarcoma in an Eyelid That Developed during Chemotherapy for Acute Myeloid Leukemia. Case Rep Ophthalmol 2016;7:25-9.

33. Klco JM, Welch JS, Nguyen TT, et al. State of the art in myeloid sarcoma. Int J Lab Hematol 2011;33:555-65.

34. Li Z, Stölzel F, Onel K, et al. Next-generation sequencing reveals clinically actionable molecular markers in myeloid sarcoma. Leukemia 2015;29:2113-6. 
35. Pastoret C, Houot R, Llamas-Gutierrez F, et al. Detection of clonal heterogeneity and targetable mutations in myeloid sarcoma by high-throughput sequencing. Leuk

Cite this article as: Liu Y, GuLiBaHa M, Yue YB, Li MW, Cao SB, Yan M. An isolated childhood myeloid sarcoma with germline MSH6 mutation-a case report. Transl Pediatr 2021;10(8):2136-2143. doi: 10.21037/tp-21-326
Lymphoma 2017;58:1008-12.

(English Language Editors: M. Bucci and J. Chapnick) 